
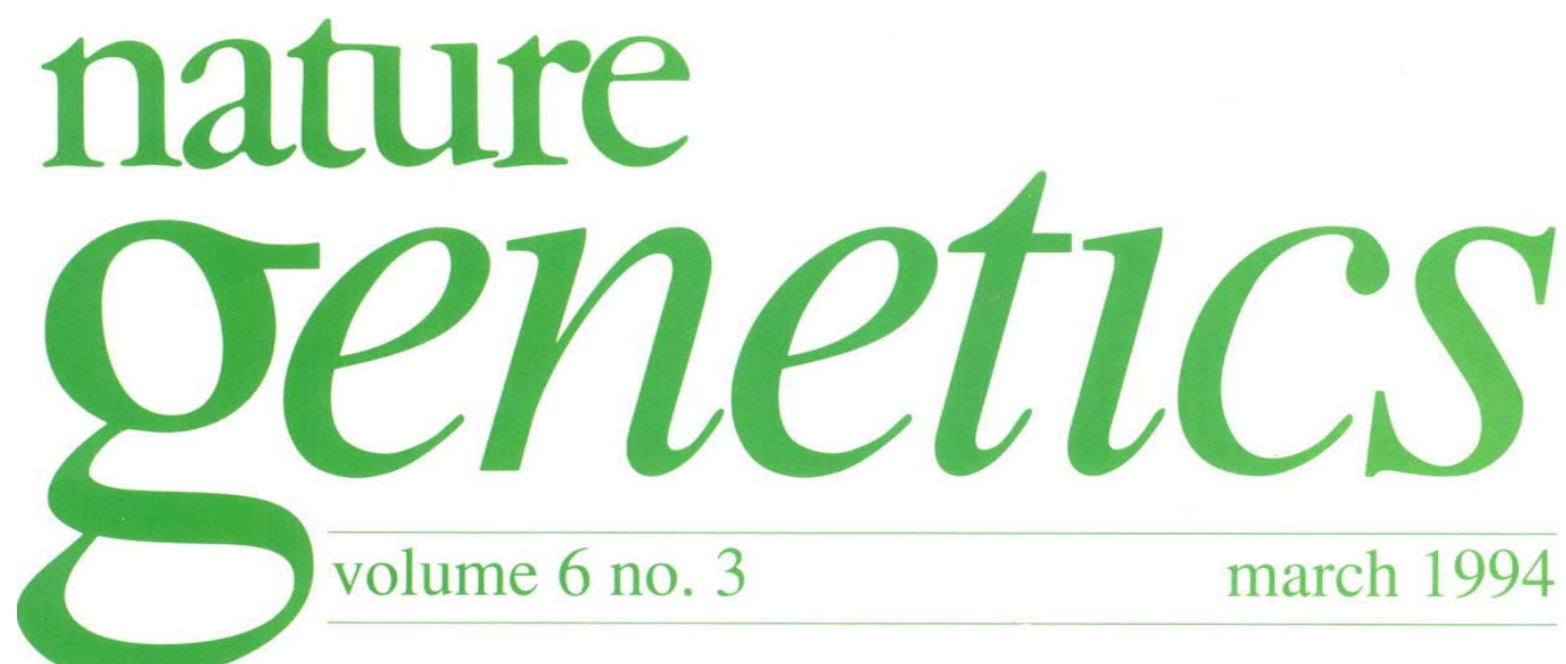

\title{
The prognosis for prostate cancer
}

A few years ago, a woman's activist remarked that if men faced the same one-in-nine risk of contracting testicular cancer that women face for breast cancer, leaving them to face a similar form of radical surgery, the public outcry would ensure swift action. It has been a long time coming, but the pressure applied by women's groups has paid off, and breast cancer research is now funded quite handsomely. This suggests that perhaps it is time that men's groups emulated their female counterparts: unlike breast cancer of late, the topic of prostate cancer has received little media attention despite the fact that the disease strikes and kills almost the same number of men as breast cancer does women, and the figures grow steadily worse ${ }^{1}$. Last year in the United States, 165,000 cases of prostate cancer were diagnosed and 35,000 men died from the disease. By comparison during the same period, 186,000 new cases of breast cancer were confirmed and 46,000 women died. Prostate cancer is the most commonly diagnosed tumour in men in the United States (having nearly doubled in the past 20 years) and the second most common cause of death (after lung cancer). But whereas the US government has devoted more than $\$ 500$ million in total to breast cancer research this year, only $\$ 51$ million has been earmarked for the study of prostate cancer.

But the public awareness of prostate cancer - a problem that men have been all too reluctant to talk about in the past - has been stimulated this year by the deaths of several celebrities in the United States. These include rock musician Frank Zappa, and actors Don Ameche (Cocoon), Bill Bixby (Dr Bruce Banner in The Incredible Hulk) and Telly Savalas (Kojak). Zappa was only 52 when he died, emphasizing that prostate cancer can strike young men as well as old. (Another recent casualty of prostate cancer was the Harvard microbial geneticist Bernard D. Davis, who died in January.) Just as the diagnosis of breast cancer in the wives of two US presidents, Betty Ford and, a decade later, Nancy Reagan, had a profound effect in generating public awareness of breast cancer, these untimely deaths are sure to provide an incentive for greater prostate research.

The small, conical prostate gland, situated at the base of the bladder and forming a fist around the urethra, fulfils an important reproductive role in younger life but causes nothing but trouble later on. A condition called benign prostatic hypertrophy impairs bladder function in $50 \%$ of men over 60 years of age, often necessitating surgery. A less invasive alternative is the drug finasteride, which inhibits $5 \alpha$ reductase (the enzyme that converts testosterone to the more potent dihydrotestosterone). Finasteride has been shown to reduce prostate size in some men and increase urinary flow, although not without side-effects ${ }^{2}$. 
This inconvenience pales in relation to malignant transformation of the prostate, which is especially common among blacks. In contrast with many cancers, there is a useful immunological blood test to diagnose prostate cancer: the measurement of a serine protease secreted exclusivelyby prostatic epithelial cells - prostate serum antigen (PSA) - provides a fairly reliable indicator of risk ${ }^{3}$ (in combination with examinations and ultrasonography). But as recent studies have shown, there is no consensus about the most effective strategy to combat the disease. Surgery, although often effective, carries risks because of the inaccessibility of the gland itself, and can leave some men incontinent or impotent. While alternatives to surgery, such as cryotherapy, are beginning to catch on, other studies are raising doubts about whether surgery is necessary at allthe so-called 'watchful waiting' policy. A recent pooled analysis of more than 800 cases from six previously published studies concluded that men diagnosed with early-stage prostate cancer, but who received no treatment, had almost as good a chance of being alive ten years later as those who had surgery or radiation therapy ${ }^{4}$. Thus conservative management may be particularly suitable for older men with shorter life expectancy.

Predisposition. Sadly, the factors that lead to increased risk of prostate cancer in the first place - apart from age - are also far from clear. Between $15 \%$ and $30 \%$ men have histologic evidence of prostate cancer by the age of 50 , regardless of country of origin, but death rates vary dramatically from country to country ${ }^{5}$. Studies have suggested an assortment of possible links, the most likely being the influence of a high fat diet on testosterone levels ${ }^{5,6}$, but other putative risk factors, including vasectomy, warrant further study. Meanwhile, the National Cancer Institute is embarking on a seven-year study involving 18,000 men to see if finasteride is also effective in preventing prostate cancer.

Knowledge of the genetic basis of prostate cancer is running about five years behind breast cancer. A few specific chromosomal losses have been noted in sporadic tumours, such as $8 p, 10 q$ and $16 \mathrm{q}$, but no individual loci have been identified. However, epidemiological studies in the Mormon population, and recent segregation studies from Patrick Walsh and colleagues at the Johns Hopkins School of Medicine, have suggested mendelian inheritance in a subset of families. Walsh is a renowned surgeon who has pioneered safer forms of surgery, sparing the nerve bundles surrounding the prostate and thereby minimizing the risk of side-effects. But two years ago, in work that closely parallels the segregation analyses that successfully predicted the existence of a dominant breast cancer gene $^{7}(B R C A 1)$ long before it was mapped to chromosome 17, Walsh's group found that an autosomal dominant locus could account for a significant proportion of early-onset prostate cancer cases $^{8}$, and perhaps as many as $9 \%$ of the total by age 85 . So far, unfortunately, the location of the putative prostate cancer susceptibility gene has not been uncovered. But there is one more tantalizing clue to be pursued. Among the hundreds of families with early-onset breast and ovarian cancer scrutinized during the past few years, some show clear evidence of a link with prostate cancer as well. The strongest evidence comes from an Icelandic group, which found a remarkably high incidence of prostate cancer among male relatives in breast cancer pedigrees ${ }^{9}$. In a small sample of early-onset breast cancer families, the increased risk of prostate cancer applied equally to men presumed to be carrying a defective $B R C A 1$ allele and those in families that did not show evidence of chromosome 17 linkage ${ }^{10}$.

Cancer researchers made great strides last year in the field of colon carcinogenesis (see Bodmer $e t$ al. ${ }^{11}$ in this issue) and breast cancer research is certain to benefit soon from similar advances, a testament to ingenuity and political pressure. But in an increasingly competitive environment for medical funding, a convincing case can be made that research into prostate cancer has languished quite long enough.

1. Lu-Yao, G.L. \& Greenberg, R.E. Lancet 343, 251-254 (1994).

2. Gormley, G.J. et al. New Engl. J. Med. 327, 1185-1191 (1992).

3. Catalona, W.J. et al. New Engl. J. Med. 324, 1156-1161 (1991).

4. Chodak, G.W. et al. New Engl. J. Med. 330, 242-248 (1994).

5. Pienta, K.J. \& Esper, P.S. J. natn. Cancer Inst. 85, 15381540 (1993).

6. Giovannucci, E.et al. J. natn. Cancer. Inst. 85, 1571-1579 (1993).

7. Newman, B., Austin, M.A., Lee, M. \& King, M-C. Proc. natn. Acad. Sci. U.S.A. 85, 1-5 (1988).

8. Carter, B.S. et al. Proc. natn. Acad. Sci. U.S.A. 89, 33673371 (1992).

9. Tulinius, H., Egilsson, V., Olafsdottir, G.H. \& Sigvaldason, H. Br. med. J. 305, 855-857 (1992).

10. Arason, A., Barkardottir, R.B. \& Egilsson, V. Am. J. hum. Genet. 52, 711-717 (1993).

11. Bodmer, W.F., Bishop, D.T. \& Karran, P. Nature Genet. 6 , 217-219 (1994).

Nature Genetics volume 6 march 1994 